\title{
An Exponential Reaching Law Sliding Mode Observer for PMSM in Rotating Frame
}

\author{
Xiao Genfu ${ }^{*}$ and Zhou Yanhui
}

School of Mechanical and Electrical Engineering, Jinggangshan University, Ji'an, Jiangxi, 343009, P.R. China

\begin{abstract}
In order to solve chattering problem of conventional sliding mode observer (SMO), this paper proposes a exponential reaching law sliding mode observer (ERL-SMO) for a permanent magnet synchronous motor (PMSM) which substitutes exponential reaching law for constant reaching law. The ERL-SMO estimates the rotor position and the angular velocity from the back electromotive force (EMF) based on rotating frame instead of fixed frame. A phase locked loop (PLL) replaces low-pass filter which commonly leads to a phase delay. The stability of the proposed exponential reaching law was verified using the Lyapunov function. The simulation results show that ERL-SMO hasn't only achieved a precise identification of PMSM speed and position, but also significantly weakened the signal chattering.
\end{abstract}

Keywords: Exponential reaching law, PMSM, SMO, sensorless, vector control.

\section{INTRODUCTION}

Recently, the usage of alternating-current (ac) motors instead of direct-current $(\mathrm{dc})$ motors has been increasing rapidly in a wide range industrial fields. There are two types of ac motors: the induction motor (IM) and the permanent magnet synchronous motor (PMSM). The PMSM is very popular in ac motor applications for various speed controls due to its high power density, higher output torque and high efficiency [1]. The IM has a simple structure, and it is easy to build. However, it is not as efficient as the PMSM is considered in terms of dynamic performance and power density. Since there is no brush in an ac motor, the size of the ac motor can be smaller with the same power and the lifetime is much longer than that of a dc motor. However, an ac motor has a more complex control system than that of a de motor [2].

Precise position data are necessary for an efficient vector control, since a PMSM receives a sinusoidal magnetic flux from the PM of the rotor. Generally, the rotor position can be detected by an absolute encoder. However, these sensors are expensive and very sensitive to environmental constraints such as vibration and temperature [3]. To overcome these problems, instead of using position sensors, a sliding mode observer (SMO) has been developed for the estimated values of the position and velocity of the rotor [4-11].

The SMO maintains good robustness of variable structure control [12]. The control loop in an ordinary observer is replaced by a sliding mode variable structure [13], and when the system error reaches the sliding mode, the system's dynamic performance entirely depends on the sliding surface, which ensures good robustness of the entire system to parameter variations [14]. Due to the discrete switch control in the SMO, chattering becomes the inherent characteristic of

\footnotetext{
*Address correspondence to this author at the School of Mechanical and Electrical Engineering, Jinggangshan University, Jiangxi, 343009, P.R. China; Tel: +867968110516; E-mail: xiaogenfu@163.com
}

the sliding mode variable structure system. As chattering cannot be completely eliminated but only reduced, in the design of the system, there should be a tradeoff between chattering reduction and system robustness. For the traditional SMO, the switch function is used as the control function. Due to switch time and space lag, the SMO presents serious chattering [15]. The estimated signal of the SMO contains high-frequency oscillation components, so one or several filters are usually used to extract the required back electromotive force (EMF) signal. In a conventional SMO, a low-pass filter and an additional position compensation of the rotor are used to reduce the chattering problem commonly found in SMO using a signum function. However, the introduction of low pass filter usually causes phase delay, which should be compensated for according to the actual angular frequency. Thus, this cannot meet the control requirements of high performance applications. An adaptive filter is proposed, which still fails to completely compensate for phase delay [16].

This paper proposes a new SMO algorithm which uses an exponential reaching law based on rotating frame instead of fixed frame. At the same time, the phase locked loop (PLL) is used to estimate rotor position and speed, eliminating the need for filters and phase compensator. The superiority of the proposed algorithm has been proved by comparison with the conventional SMO through experiments.

This paper consists of five sections, including the introduction. Section II introduces the conventional SMO, and section III proposes the new SMO. Section IV illustrates the experimental results, and section $\mathrm{V}$ draws the conclusions relating to the contributions of this paper.

\section{CONVENTIONAL SMO}

\subsection{PMSM Model in Fixed Frame}

The PMSM consists of a rotor with a PM and a stator with a three-phase winding. It can be simplified to a twophase model though coordinate transformation. 
The state equations, where the stator current is a state variable of the fixed frame voltage equation, can be represented as:

$$
\left\{\begin{array}{l}
\frac{d i_{\alpha}}{d t}=-\frac{R_{s}}{L_{s}} i_{\alpha}-\frac{1}{L_{s}} e_{\alpha}+\frac{1}{L_{s}} v_{\alpha} \\
\frac{d i_{\beta}}{d t}=-\frac{R_{s}}{L_{s}} i_{\beta}-\frac{1}{L_{s}} e_{\beta}+\frac{1}{L_{s}} v_{\beta}
\end{array}\right.
$$

Where $i_{\alpha}, i_{\beta}, e_{\alpha}, e_{\beta}$, and $v_{\alpha}, v_{\beta}$ represent the current, electromotive force, and voltage for each phase, respectively, in the fixed frame. $R_{s}$ and $L_{s}$ represent the stator resistance and inductance, respectively.

The electromotive force for each phase can be represented in the fixed frame as:

$\left\{\begin{array}{c}e_{\alpha}=-\psi_{f} \omega_{f} \sin \theta \\ e_{\beta}=-\psi_{f} \omega_{f} \cos \theta\end{array}\right.$

Where $\psi_{f}, \omega_{f}$ and $\theta$ represent the magnetic flux of the permanent magnet, the electric angular velocity, and the rotor angle, respectively.

The rotor angle and speed can be represented in the fixed frame as:

$$
\left\{\begin{array}{c}
\theta=\arctan \left(-\frac{e_{\alpha}}{e_{\beta}}\right) \\
\omega=\frac{d \theta}{d t}
\end{array}\right.
$$

\subsection{The Principle of Sliding Mode Control System}

If the system state variable is defined as:

$\dot{x}(t)=f(x, u, t), x \in R^{n}, u \in R^{m}, t \in R$

The switch function is represented as:

$s(x), s \in R^{m}$

And the control variable is defined as:

$u(x)= \begin{cases}u^{+}(x) & s(x)>0 \\ u^{-}(x) & s(x)<0\end{cases}$

Where, $u^{+}(x) \neq u^{-}(x)$.

If a system complies with the previous formula and meets the sliding mode existence, accessibility, stability, and good dynamic quality, the system is called the sliding mode control system.

\subsection{Conventional SMO}

For the implementation of the sliding mode observer, the sliding surfaces below are selected as:

$s(x)=\hat{i}_{s}-i_{s}$

Where $\hat{i}_{s}$ is estimated current, $i_{s}$ is actual current.

According to the PMSM equation in the $\alpha-\beta$ coordinate system (fixed frame), the conventional SMO is constructed as follows:

$$
\begin{aligned}
& \frac{d \hat{i}_{\alpha}}{d t}=-\frac{R}{L} \hat{i}_{\alpha}+\frac{u_{\alpha}}{L}-\frac{\lambda}{L} \operatorname{sign}\left(\hat{i}_{\alpha}-i_{\alpha}\right) \\
& \frac{d \hat{i}_{\beta}}{d t}=-\frac{R}{L} \hat{i}_{\beta}+\frac{u_{\beta}}{L}-\frac{\lambda}{L} \operatorname{sign}\left(\hat{i}_{\beta}-i_{\beta}\right)
\end{aligned}
$$

Where $\operatorname{sign}(s)$ is sign function, $\lambda$ is switching gain.

Through a low pass filter, the high frequency components in $\operatorname{sign}(\hat{i}-i)$ are filtered and back EMF estimated value $\hat{e}_{s}$ is obtained as follow:

$\left\{\begin{array}{l}\hat{e}_{\alpha}=\frac{\omega_{c}}{s+\omega_{c}} \lambda \cdot \operatorname{sign}\left(\hat{i}_{\alpha}-i_{\alpha}\right) \\ \hat{e}_{\beta}=\frac{\omega_{c}}{s+\omega_{c}} \lambda \cdot \operatorname{sign}\left(\hat{i}_{\beta}-i_{\beta}\right)\end{array}\right.$

Where $\omega_{c}$ is cut-off frequency of the low pass filter.

The angle of the rotor $\hat{\theta}$ can be estimated by back EMF, and the rotation speed $\hat{\omega}$ can be obtained by differentiating the angle.

$\hat{\theta}=-\arctan \left(\frac{\hat{e}_{\alpha}}{\hat{e}_{\beta}}\right)$

$\hat{\omega}=\frac{d \hat{\theta}}{d t}$

The estimated angular position needs be compensated for the phase delay caused by a low pass filter. The final estimated value of the rotor position $\hat{\theta}_{z}$ is the sum of $\hat{\theta}$ and compensation value with related motor velocity.

$\Delta \theta=\tan ^{-1}\left(\omega / \omega_{c}\right)$

$\hat{\theta}_{z}=\hat{\theta}+\Delta \theta$

Fig. (1) shows the conventional SMO where the sign function is used as the switching function, and the low pass filter (LPF) is used to eliminate the chattering effects from the switching, where $\lambda$ value is determined by the Lyapunov function. 


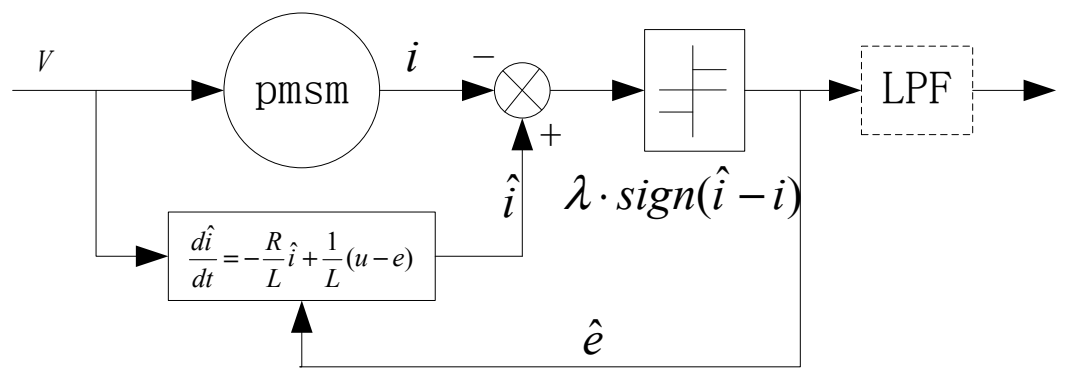

Fig. (1). The construct of conventional SMO.

\section{EXPONENTIAL REACHING LAW SMO}

\subsection{PMSM Model in Rotating Frame}

The PMSM mathematical model in the $d-q$ coordinate system(rotating frame) can be expressed as:

$$
\begin{gathered}
\frac{d i_{d}}{d t}=-\frac{R}{L_{d}} i_{d}+\frac{1}{L_{d}} u_{d}+\frac{L_{q} \omega_{e}}{L_{d}} i_{q}-\frac{1}{L_{d}} E_{d} \\
\frac{d i_{q}}{d t}=-\frac{R}{L_{q}} i_{q}+\frac{1}{L_{q}} u_{q}+\frac{L_{d} \omega_{e}}{L_{q}} i_{d}-\frac{1}{L_{q}} E_{q} \\
J \frac{d \omega_{r}}{d t}=T_{e}-B \omega_{r}-T_{L} \\
T_{e}=\frac{3}{2} p\left(\psi_{f} i_{q}+\left(L_{d}-L_{q}\right) i_{d} i_{q}\right)
\end{gathered}
$$

Where $\mathrm{d}$, q represent $\mathrm{d}$, q-axis component respectively, and $\omega_{e}$ represents rotor electrical angular velocity, and $E_{d}$, $E_{q}$ represent EMF in the $\mathrm{d}-\mathrm{q}$ coordinate system, $\mathrm{p}$ is the number of pole pairs of the motor, $\psi_{f}$ is flux of permanent magnet, $T_{e}$ is electromagnetic torque, $\mathrm{J}$ is Moment of inertia, and $\omega_{r}$ represents mechanical angular velocity of rotor, and $\mathrm{B}$ is rotor friction coefficient.

\subsection{Exponential Reaching Law}

Exponential reaching law is the sum movement of exponential $e^{-\eta t}$ and constant as follows:

$\dot{s}=-\delta \operatorname{sgn}(s)-k s, \delta>0, k>0$

Where $\delta$ and $k$ are constants.

With respect to the constant reaching law, exponential reaching law increases the initial speed of the system exponentially, and its parameters $\mathrm{k}$ and $\delta$ can be adjusted. Exponential reaching law not only can improve the quality of the sliding mode dynamic arrival process, but can also weaken the control signal chattering.

Reaching condition of sliding mode control system can be expressed as:
$S \dot{S}<0$

According to formula (15)

$s \dot{s}=-s[k s+\delta \operatorname{sign}(s)]=-k s^{2}-\delta \operatorname{sign}(s) s=-k s^{2}-\delta|s|$

Due to $\mathrm{k}>0, \delta>0$, we can know $s \dot{s}<0$.

We select formula (18) as Lyapunov function.

$V(x)=\frac{1}{2}\left(s_{1}^{2}+s_{2}^{2}\right)$

The derivation of formula (18) is:

$\dot{V}(x)=s_{1} \dot{s}_{1}+s_{2} \dot{s}_{2}$

Based on the above analysis, we know $s \dot{s}<0$ and $\dot{V}(x)$ $<0$, which can prove that exponential reaching law has asymptotic stability in view of Lyapunov.

\subsection{Exponential Reaching Law SMO}

In order to reduce the chattering of conventional SMO, switching function is replaced by exponential reaching law. Exponential reaching law SMO(ERL-SMO) can be expressed as follows:

$$
\left\{\begin{array}{c}
\frac{d i_{d}}{d t}=-\frac{R}{L_{d}} i_{d}+\frac{1}{L_{d}} u_{d}+\frac{L_{q} \omega_{e}}{L_{d}} i_{q}-\frac{1}{L_{d}}\left(\lambda \operatorname{sgn}\left(s_{d}\right)-\eta s_{d}\right) \\
\frac{d i_{q}}{d t}=-\frac{R}{L_{q}} i_{q}+\frac{1}{L_{q}} u_{q}+\frac{L_{d} \omega_{e}}{L_{q}} i_{d}-\frac{1}{L_{q}}\left(\lambda \operatorname{sgn}\left(s_{q}\right)-\eta s_{q}\right) \\
s_{d}=\hat{i}_{d}-i_{d} \\
s_{q}=\hat{i}_{q}-i_{q}
\end{array}\right.
$$

The back EMF of motor can be expressed as:

$$
\left\{\begin{array}{c}
e_{d}^{*}=-\lambda \operatorname{sgn}\left(s_{d}\right)-\eta s_{d} \\
e_{q}^{*}=-\lambda \operatorname{sgn}\left(s_{q}\right)-\eta s_{q}
\end{array}\right.
$$

The construct of ERL-SMO is shown in Fig. (2).

\subsection{Estimation of Rotor Position and Velocity}

The low pass filter in conventional SMO will lead to a certain position estimation phase difference. Phase locked 


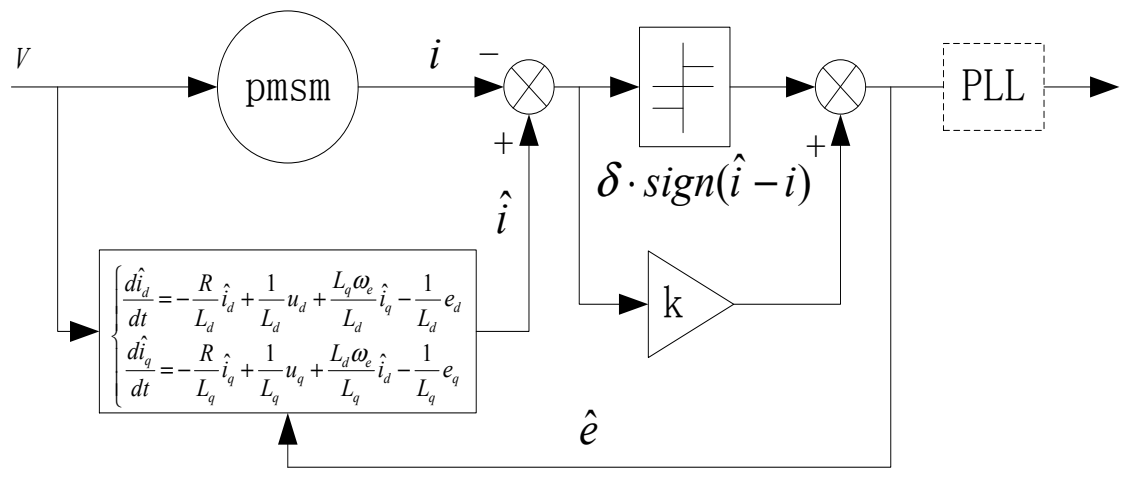

Fig. (2). The construct of ERL-SMO.

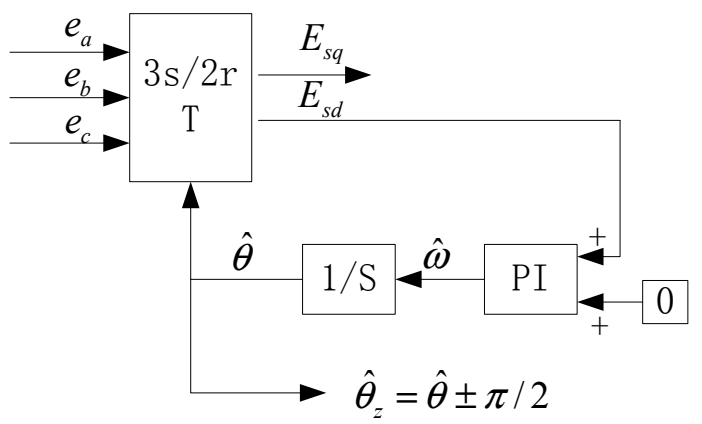

Fig. (3). The construct of PLL.

loop (PLL) in ERL-SMO will replace low pass filter to gain estimated value of rotor position and velocity. lows:

EMF of three phase stator windings is expressed as fol-

$$
\left\{\begin{array}{l}
e_{a}=E \cos \omega t \\
e_{b}=E \cos \omega t-120^{\circ} \\
e_{c}=E \cos \omega t+120^{\circ}
\end{array}\right.
$$

Where $\theta=\omega t$, and $\omega=2 \pi f=\pi p n / 30, \mathrm{p}$ is the number of pole pairs of the motor, and $n$ is the velocity of the motor.

According to the synchronous rotating coordinate transformation theory, the transformation matrix of $\mathrm{d}-\mathrm{q}$ coordinate system is expressed as follows:

$T=\frac{2}{3}\left[\begin{array}{ccc}\cos \hat{\omega} t & \cos \left(\hat{\omega} t-120^{\circ}\right) & \cos \left(\hat{\omega} t+120^{\circ}\right) \\ -\sin \hat{\omega} t & -\sin \left(\hat{\omega} t-120^{\circ}\right) & -\sin \left(\hat{\omega} t+120^{\circ}\right) \\ 1 / 2 & 1 / 2 & 1 / 2\end{array}\right]$

Where $\hat{\theta}=\hat{\omega} t$ is the phase angle calculated by PLL, and $\Delta \theta=\hat{\theta}-\theta$ is the error of phase lock. The target of PLL is $\Delta \theta=0$.

The rotating coordinate transformation of three-phase induced electromotive force can be expressed as follows:

$$
\left[\begin{array}{c}
E_{q} \\
E_{d}
\end{array}\right]=\frac{1}{3} M\left[\begin{array}{c}
\sin (\hat{\theta}-\theta) \\
\cos (\hat{\theta}-\theta) \\
\sin (\hat{\theta}+\theta) \\
\cos (\hat{\theta}+\theta)
\end{array}\right]=\frac{1}{3} M\left[\begin{array}{c}
\sin \Delta \theta \\
\cos \Delta \theta \\
\sin (\hat{\theta}+\theta) \\
\cos (\hat{\theta}+\theta)
\end{array}\right]
$$

The element of matrix $\mathrm{M} 2 * 4$ is: $\mathrm{M}_{11}=0, \mathrm{M}_{12}=3 \mathrm{E}, \mathrm{M}_{13}=0$, $\mathrm{M}_{14}=0, \mathrm{M}_{21}=-\mathrm{M}_{12}, \mathrm{M}_{22}=\mathrm{M}_{11}, \mathrm{M}_{23}=-\mathrm{M}_{14}, \mathrm{M}_{24}=\mathrm{M}_{13}$.

When phase is locked by PLL, we know $\hat{\theta}=\theta$, and above formula can be simplified to:

$\left[\begin{array}{c}E_{q} \\ E_{d}\end{array}\right]=\frac{1}{3}\left[\begin{array}{cc}M_{11} & M_{12} \\ -M_{12} & M_{11}\end{array}\right]$
$\left[\begin{array}{c}\sin \Delta \theta \\ \cos \Delta \theta\end{array}\right]=\left[\begin{array}{cc}E_{s d} & E_{s q} \\ -E_{s q} & E_{s d}\end{array}\right]\left[\begin{array}{l}0 \\ 1\end{array}\right]$

According to the definition of synchronous rotating $d-q$ coordinate system and formula (25), we may know $E_{s d}=M_{11} \cos \theta=0$.

The PLL can be constructed to gain PMSM speed and rotor position through former formula as shown in Fig. (3). 


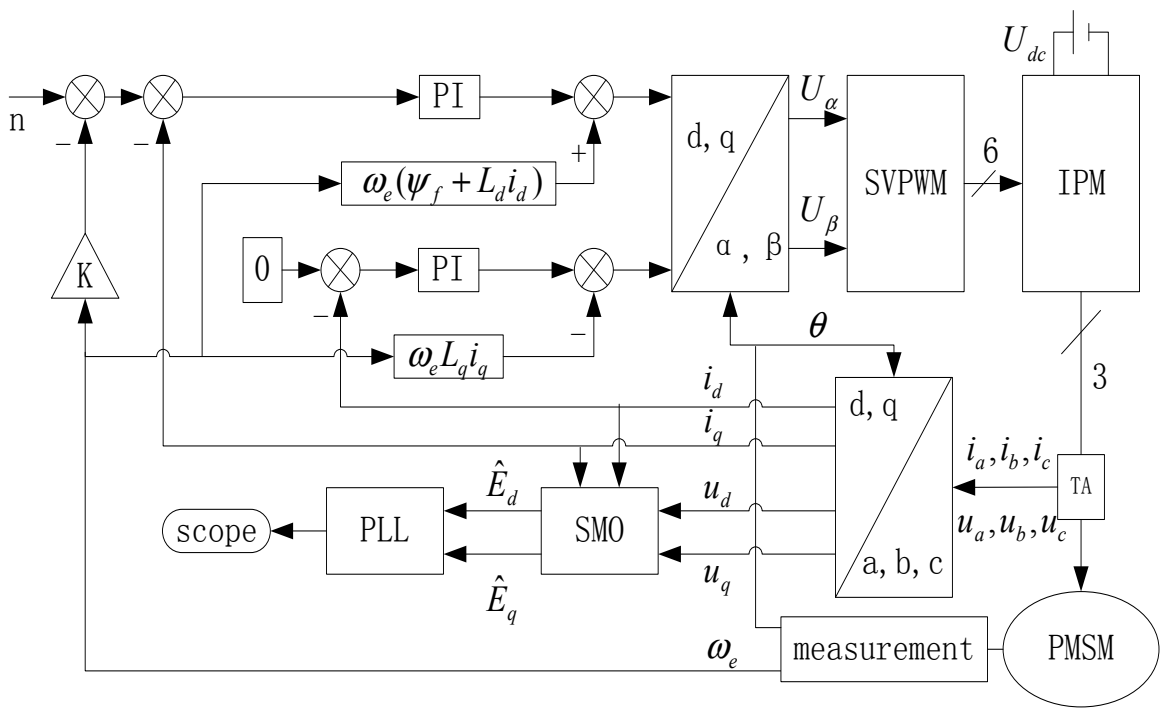

Fig. (4). Block diagram of sensorless control system.

Table 1. PMSM parameters.

\begin{tabular}{|c|c|c|}
\hline Parameters & Unit & Value \\
\hline \hline Stator phase resistance & Ohm & 0.0192 \\
\hline Inductances(Ld) & $\mathrm{H}$ & 0.0105 \\
\hline Flux linkage & $\mathrm{V} . \mathrm{s}$ & 10.228 \\
\hline Inertia & $\mathrm{J}\left(\mathrm{kg} \cdot \mathrm{m}^{\wedge} 2\right)$ & 16000 \\
\hline Friction factor & N.m.s & 1600 \\
\hline Pole pairs & $\mathrm{P}$ & 30 \\
\hline
\end{tabular}

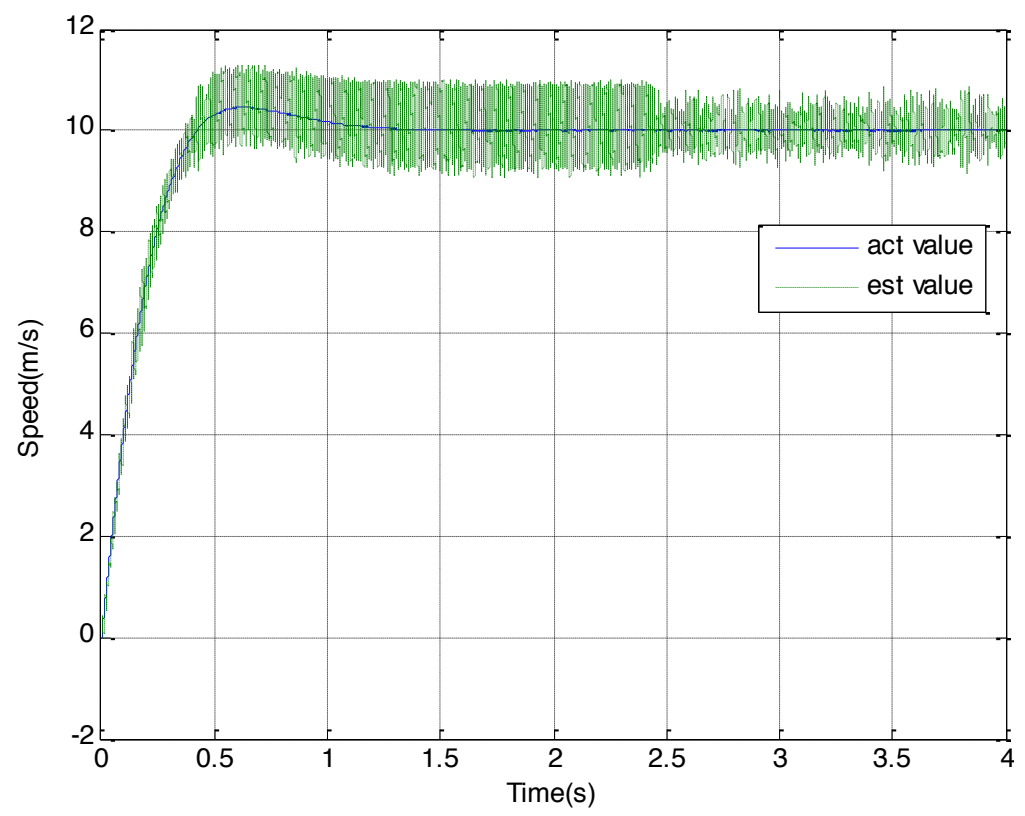

Fig. (5). Speed estimation of conventional SMO. 


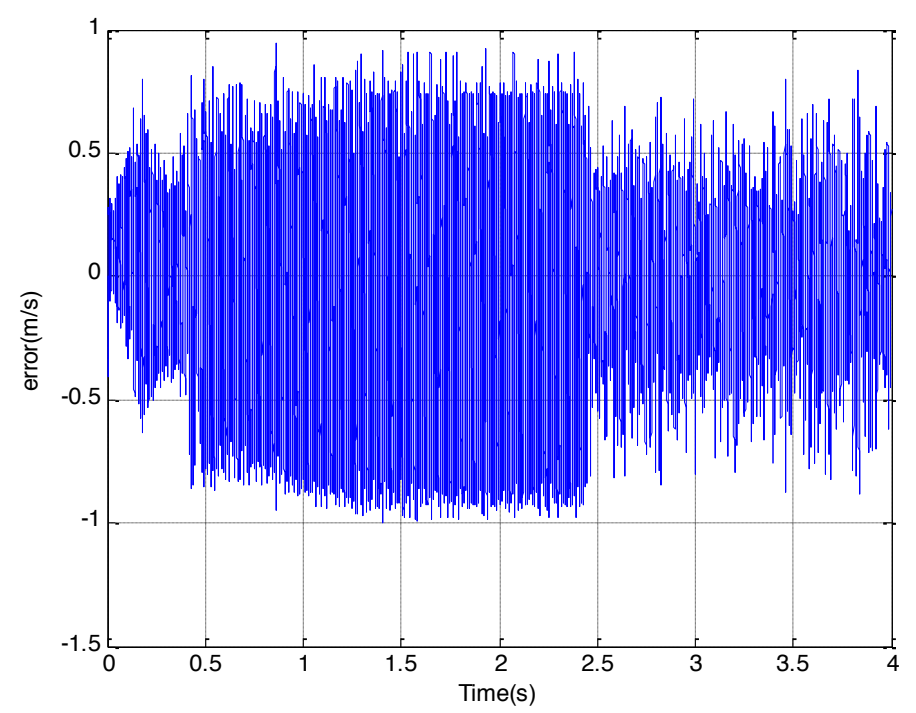

Fig. (6). Error of conventional SMO speed.

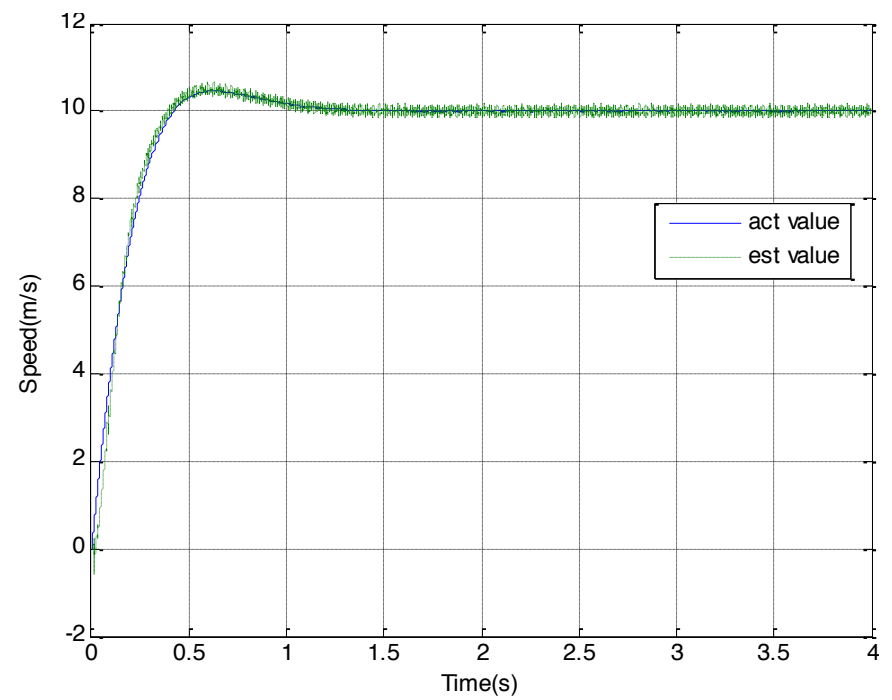

Fig. (7). Speed estimation of ERL-SMO.

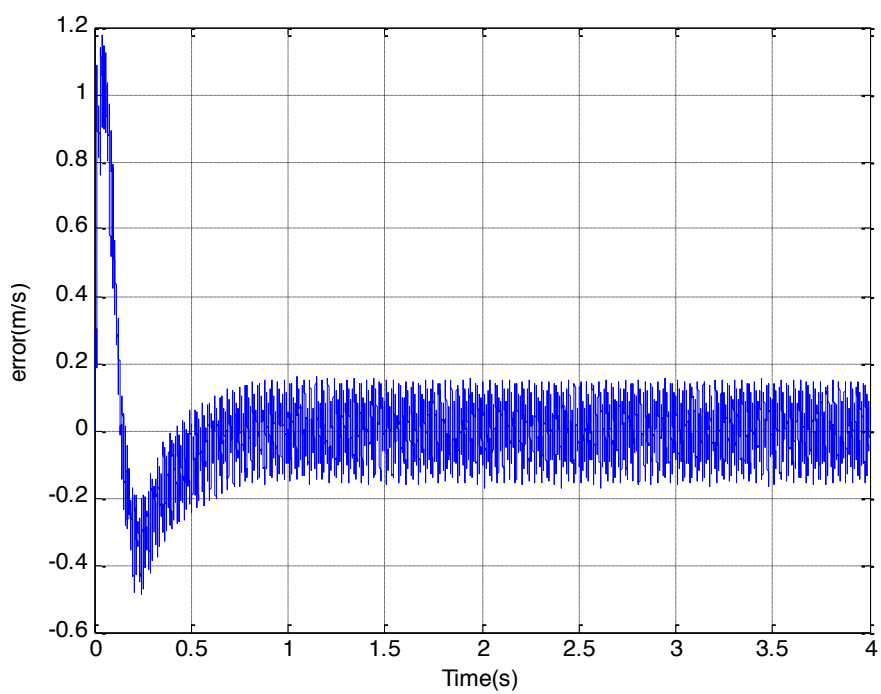

Fig. (8). Error of ERL-SMO speed estimation. 


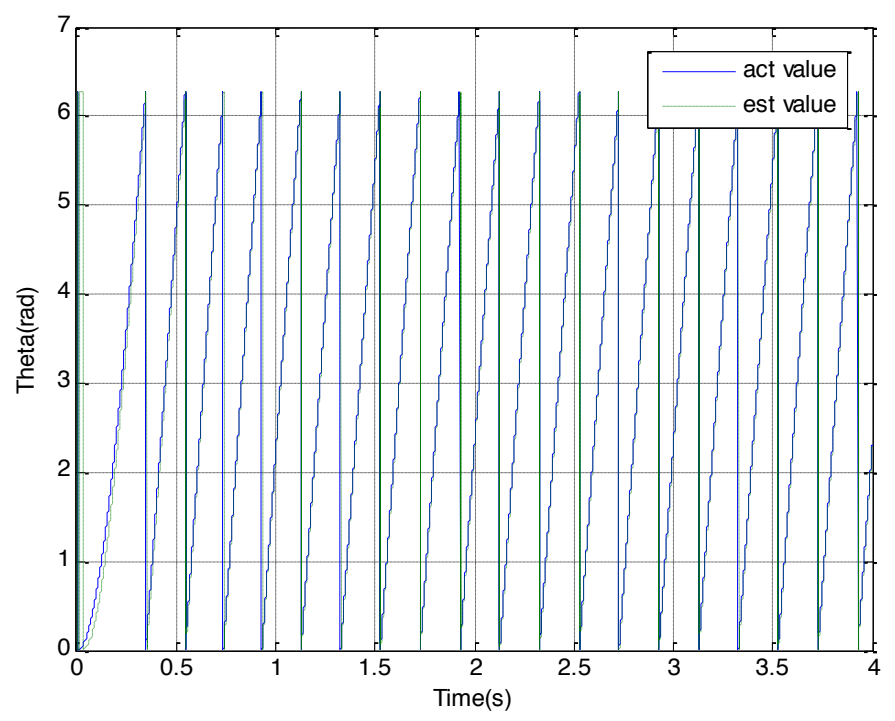

Fig. (9). Position estimation of ERL-SMO.

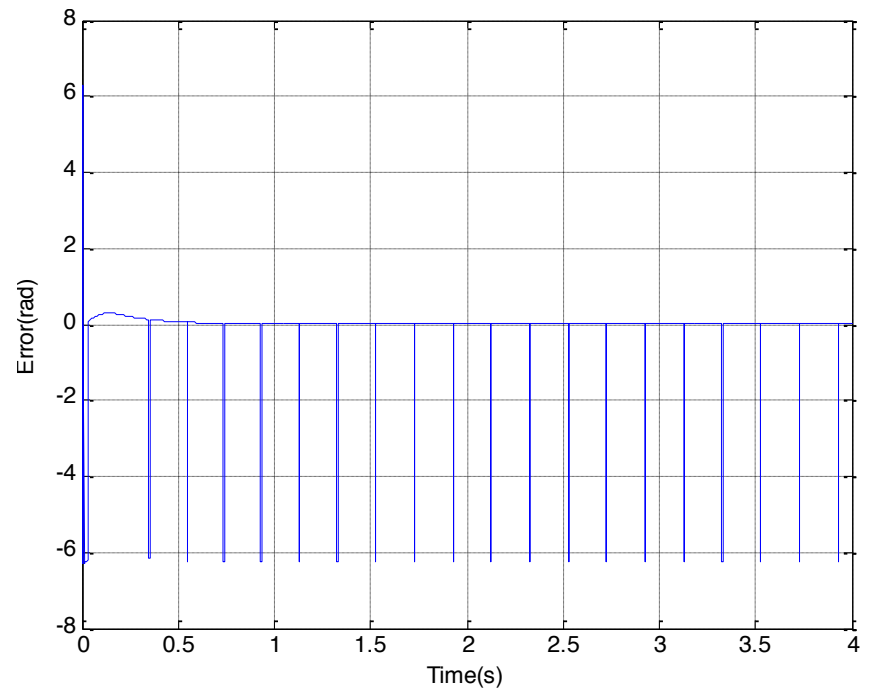

Fig. (10). Error of position estimation.

\section{SIMULATIONS AND ANALYSIS OF RESULTS}

In order to verify the effectiveness, the ERL-SMO is simulated in Matlab/Simulink. The PMSM parameters are shown in Table 1.

The vector control method is adopted, using a step function as speed input. Because of the mutual coupling of $\mathrm{d}$, qaxis variable, feed-forward decoupling control strategy is applied. Sensorless control system block diagram is shown in Fig. (4).

Figs. $(5,6)$ are the PMSM speed estimated value and the speed error of the conventional SMO. As can be seen, because of the switch function, there is a big chattering.

Figs. $(7,8)$ are the PMSM speed estimated value and the speed error of the ERL-SMO. As can be seen, in the dynamic process, ERL-SMO can track actual speed value quickly. After entering the steady state, the estimated error is close to zero.
Figs. $(9,10)$ are the PMSM rotor position estimated value through the ERL-SMO and the estimation error of the rotor position. As can be seen, error of position estimation is small and the estimation of the rotor position is accurate.

\section{CONCLUSION}

This paper has proposed an ERL-SMO for a sensorless system for a PMSM. The stability of the new SMO has been proved with the use of a Lyapunov stability analysis. The chattering problem in the conventional SMO was resolved by using the exponential reaching law instead of the conventional sign function. A PLL was employed to reduce the estimated error associated with low pass filter. The superiority of ERL-SMO has been confirmed through simulation. The ERL-SMO improves the reliability and accuracy of prediction of the rotor position, having significance in terms of the practical application and theory research. 


\section{CONFLICT OF INTEREST}

The authors confirm that this article content has no conflict of interest.

\section{ACKNOWLEDGEMENTS}

This work was supported by Science and Technology Support Project of Jiangxi Province of China (No.20142BBE50057).

\section{REFERENCES}

[1] A. Wang, and X. Jia, "A new exponential reaching law of sliding mode control to improve performance of permanent magnet synchronous motor," IEEE Trans. Magn., vol. 49, pp. 2409-2412, 2013.

[2] P. Pillay, and R. Krishnan, "Application characteristics of permanent magnet synchronous and brushless dc motor for servo drive," IEEE Trans. Ind. Appl., vol. 27, pp. 986-996, 1991.

[3] F. Parasiliti, R. Petrella, and M. Tursini, "Sensorless speed control of a PM synchronous motor by sliding mode observer," Proc. IEEE ISIE, vol. 3, pp. 1106-1111, 1997.

[4] P. Vaclavek, and P. Blaha, "Lyapunov function-based flux and speed observer for ac induction motor sensorless control and parameters estimation," IEEE Trans. Ind. Electron., vol. 53, pp. 138145, 2006.

[5] S. Ichikawa, M. Tomita, S. Doki, and S. Okuma, "Sensorless control of permanent magnet synchronous motors using online parameter identification based on system identification theory," IEEE Trans. Ind. Electron., vol. 53, pp. 363-372, 2006.

[6] S. Chi, Z. Zhang, and L. Xu, "Sliding mode sensorless control of direct drive PM synchronous motors for washing machine applications," IEEE Trans. Ind. Appl., vol. 45, pp. 582-590, 2009.
[7] H. Kim, and J. Son, "A high-speed sliding-mode observer for the sensorless speed control of a PMSM," IEEE Trans. Ind. Electron., vol. 58, pp. 4069-4077, 2011.

[8] Z. Qiao, and T. Shi, "New sliding-mode observer for position sensorless control of permanent-magnet synchronous motor," IEEE Trans. Ind. Electron., vol. 60, pp. 710-719, 2013.

[9] H. Lee, and J. Lee, "Design of iterative sliding mode observer for sensorless PMSM control," IEEE Trans. Control Syst. Technol., vol. 21, 2013.

[10] B. Thiago, and F. M. Vinicius, "Discrete-time sliding mode observer for sensorless vector control of permanent magnet synchronous machine," IEEE Trans. Ind. Electron., vol. 61, pp. 1679-1691, 2014.

[11] Y. Feng, X. Yu, and F. Han, "High-order terminal sliding-mode observer for parameter estimation of a permanent magnet synchronous motor," IEEE Trans. Ind. Electron., vol. 60, no. 10, pp. 1272 4280, 2013.

[12] S. Wang, and X. Li, "Computer-controlled variable structure systems: The state of the art". IEEE Trans. Ind. Informat., vol. 8, pp. 197-205, 2012.

[13] G. Foo, and M. F. Rahman, "Rotor position and speed estimation of avariable structure direct torque controlled IPM synchronous motor drive at very low speeds including standstill," IEEE Trans. Ind. Electron., vol. 57, pp. 3715-3723, 2010.

[14] M. L. Corradini, G. Ippoliti, S. Longhi, and G. Orlando, "A quasi sliding mode approach for robust control and speed estimation of PM synchronous motors," IEEE Trans. Ind. Electron., vol. 59, pp. 1096-1104, 2012.

[15] G. Tarchala, "Influence of the sign function approximation form on performance of the sliding-mode speed observer for induction motor drive," In: Proceeding of IEEE International Symponysim. Ind. Electron., 2011, pp. 1397-1402.

[16] G. L. Cascella, N. Salvatore, and L. Salvatore, "Adaptive slidingmode observer for field oriented sensorless control of SPMSM," Proc. IEEE Ind. Appl. Conf., vol. 2, pp. 1137-1143, 2003.

(C) Genfu and Yanhui; Licensee Bentham Open.

This is an open access article licensed under the terms of the Creative Commons Attribution Non-Commercial License (http://creativecommons.org/licenses/by$\mathrm{nc} / 4.0 /$ ) which permits unrestricted, non-commercial use, distribution and reproduction in any medium, provided the work is properly cited. 